\title{
High Frequency Individual Cylinder Estimation for Control of Diesel Engines
}

\author{
J. Chauvin ${ }^{1,2 *}$, G. Corde 1 , P. Moulin ${ }^{1}$, N. Petit ${ }^{2}$ and P. Rouchon ${ }^{2}$ \\ 1 Institut français du pétrole, 1 et 4, avenue de Bois-Préau, 92852 Rueil-Malmaison Cedex - France \\ 2 Centre Automatique et Systèmes, École des Mines de Paris, 60 blvd Saint Michel, 75006 Paris - France \\ e-mail: jonathan.chauvin@ifp.fr - gilles.corde@ifp.fr - philippe.moulin@ifp.fr - \\ petił@cas.ensmp.fr - rouchon@cas.ensmp.fr \\ *Corresponding author
}

\begin{abstract}
Résumé - Observateur cylindre à cylindre haute fréquence pour le contrôle des moteurs Diesel - Les normes de pollution de plus en plus rigoureuses ont imposé un large intérêt pour la réduction d'émissions. Deux stratégies peuvent être considérées : post-traitement et réduction d'émissions moteur. Pour les moteurs Diesel, le post-traitement a un coût élevé induit par la technologie et par le contrôle de ces systèmes. Dans ce contexte, le mode de combustion Highly Premixed Combustion (HPC) est devenu une source d'intérêt ces dernières années. Il représente une des voies les plus prometteuses pour la nouvelle génération des moteurs Diesel en utilisant des taux élevés de recirculation des gaz d'échappement (EGR). Des essais sur banc moteur ont apporté la preuve de la réduction significative d'émission. Cependant, l'application réelle sur véhicule implique le fonctionnement du moteur en transitoire qui est encore loin des essais en stabilisé au banc moteur. Plusieurs importants défis doivent être surmontés. Avec cette technologie de combustion, l'équilibrage de couple cylindre à cylindre est une nécessité. En effet, un léger déséquilibre entre les cylindres peut avoir des conséquences dramatiques et induire un bruit important, une possible extinction et des émissions polluantes plus élevées. Dans ce sens, nous développons des observateurs haute fréquence de la combustion. Ces derniers servent d'outils aux stratégies de contrôle temps réel.
\end{abstract}

\begin{abstract}
High Frequency Individual Cylinder Estimation for Control of Diesel Engines - Increasingly stringent pollution regulations have spurred a broad interest in the reduction of engine emissions. Two strategies can be considered: after-treatment or engine emissions reduction. For Diesel engines, after-treatment has a high cost induced by the required technology and implementation issues. In this context, the Highly Premixed Combustion combustion mode (HPC) has emerged as a topic of major interest in recent years. It represents one of the most promising ways for new generation of CI engines using high Exhaust Gas Recirculation (EGR) rates. Experimentation on the testbench brought the proof of significant emission reduction. However, actual vehicle implementation implies frequent transient which fall far beyond steady state experimentation on the testbench. Several key challenges have to be addressed. With this combustion technology, accurate torque balancing at all engine modes is a requirement. Even slight unbalance between the cylinders can have dramatic consequences and induce important noise, possible stall and higher emissions. To achieve this goal, we develop high frequency individual cylinder estimators. These serve as tools for real time control strategies.
\end{abstract}




\section{INTRODUCTION}

Increasingly stringent pollution norms regulations have spurred a broad interest in the reduction of engine emissions. Two strategies can be considered: after-treatment or engine emissions reduction. For Diesel engines, after-treatment has a high cost induced by the required technology and implementation issues. In this context, the Highly Premixed Combustion combustion mode (HPC) has emerged as a topic of major interest in recent years. It represents one of the most promising ways for new generation of CI engines using high Exhaust Gas Recirculation (EGR) rates. Experimentation on the testbench brought the proof of significant emission reduction [1-4]. However, actual vehicle implementation implies frequent transient which fall far beyond steady state experimentation on the testbench. Several key challenges have to be solved. With this combustion technology, accurate torque balancing at all engine modes is a requirement. Even slight unbalance between the cylinders can have dramatic consequences and induce important noise, possible stall and higher emissions. To achieve this goal, we develop high frequency individual cylinder estimators. These serve as tools for real time control strategies.

The combustion torque characterizes the performance of the engine and is the result of various inputs such as injection quantity and timing, EGR rate.... Ideally, this torque could be measured using fast pressure sensors in each cylinder. Unfortunately, high cost and low reliability prevent these sensors from reaching commercial products. On-line estimation is necessary. Another way to control the combustion torque is to control individual Air Fuel Ratios (AFR) which is a good representation of the torque produced by a Diesel engine. In theory, all the cylinders should have the same AFR since they have the same injection set-point. Not surprisingly, due to inherent flaws of the injection system (pressure waves, mechanical tolerances, ...), identical total mass of fuel injected in each cylinder is very difficult to achieve by design. Again, an estimator is a prerequisite to controlling the individual cylinder torque.

For both estimation problems we propose a physics-based approach. Using balance equations, crankshaft dynamics and exhaust manifold balance respectively, we underline the role of periodicity in the design of nonlinear observers. In the first case we use as the only sensor the crankshaft instantaneous speed sensor. In the other one we use the Air Fuel Ratio sensor placed downstream the turbine as the only sensor. These observers have common properties: their computational requirements are low, the tuning is made easy by using the periodicity of the corresponding equations, and estimation is performed at a high frequency $\left(6^{\circ}\right.$ crankshaft).

The contribution is as follows. In Section 1, we expose the engine set up and the NADI ${ }^{\mathrm{TM}}$ engine configuration for HPC/conventional combustion mode. In Section 2, we present the tool chain from simulation (AMESim) to experimental testbench through a Hardware in the Loop ACEbox rapid prototyping system developed by IFP with Matlab ${ }^{\circledR /}$ xPCTarget [5] technology. The instantaneous combustion torque observer and the individual AFR observer are detailed in Section 3 and in Section 4 respectively. These observers are presented theoretically along with their corresponding physical model. Real time testbench results are presented and underline the relevance of such a strategy. Conclusions and first results of control with the presented observers are finally given.

\section{ENGINE PRESENTATION}

\subsection{Highly Premixed Combustion Technological Solution}

In order to get good performances in terms of torque, consumption and pollutant emission, it is important to properly mix fuel and air before starting combustion. As a lot of works have pointed out that port fuel injection drawbacks are a bar to putting such engines into production, the first development axis was to find a combustion system allowing HPC combustion using the common rail fuel injection which can make multiple injections with conventional injector nozzles. Although the desirable low temperature combustion allows a substantial reduction of $\mathrm{NO}_{x}$ formation and in some cases the formation of particulates, this way of investigation involves some difficulties to implement:

- Avoid wall impingement and promote fuel vaporisation and air/fuel mixing, so as to limit particulate and $\mathrm{HC}$ emissions and to prevent oil dilution.

- Control combustion over the whole operation range: at high load, operating conditions at high Fuel/Air equivalence ratio are limited by combustion stability, excessive heat release, knock and noise.

- Control of combustion: it is the key point in HPC to extend the operating range and power output.

To summarize, the HPC mode permits very low $\mathrm{NO}_{x}$ and particulate emissions but it favors $\mathrm{HC}$ and $\mathrm{CO}$ emissions and increases noise level at part loads. The NADI ${ }^{\mathrm{TM}}$ concept helps to reduce these problems.

\subsection{NADI ${ }^{\mathrm{TM}}$ Engine Concept}

\subsubsection{Overview}

Since 2000, IFP has been working to solve the problems due to HPC and has developed the NADI ${ }^{\mathrm{TM}}$ (Narrow Angle Direct Injection) concept which is based on a dual mode approach, using HPC at low and medium loads and conventional mode combustion at high and full loads [3]. In a first stage, the latest development of this concept has been achieved on a single cylinder engine. At full load, the NADI ${ }^{\mathrm{TM}}$ system is consistent with future Diesel engine power density standards which means that $60 \mathrm{~kW} / \mathrm{l}$ has been reached. In HPC mode, above $1500 \mathrm{rpm}, 0.85 \mathrm{MPa}$ of BMEP has been reached with emissions of NOx under 
$0.05 \mathrm{~g} / \mathrm{kWh}$ which is 100 times lower than a conventional Diesel engine [4]. To be fully compatible with the future stringent standard levels and thanks to an appropriate multiple staged injection strategy, a large reduction of combustion noise was reached at high load. A first application on multi-cylinder has also been studied. In this case, $0.60 \mathrm{MPa}$ of BMEP is obtained in HPC mode above $1500 \mathrm{rpm}$ with emissions of $\mathrm{NO}_{x}$ under $0.1 \mathrm{~g} / \mathrm{kWh}$ [6].

\subsubsection{Dual Combustion Mode Engine}

The NADI ${ }^{\mathrm{TM}}$ engine works with two separate combustion modes: highly premixed combustion with high EGR rates and conventional combustion with conventional fuel multiinjection. The operating condition range of the European driving cycle is mainly located in the HPC area which allows significant reduction of the vehicle pollutant emission.

\subsubsection{Injection Strategy}

The NADI ${ }^{\mathrm{TM}}$ concept is based on the use of multiple injection strategies depending on engine load and speed in order to control the combustion according to the agreed targets. At low engine load, early injections are helpful to obtain a good fuel/air mixing before the combustion in order to achieve near zero $\mathrm{NO}_{x}$ and particulate emissions with a good fuel consumption and a very low noise level. The injection strategies on this low load are adapted to minimise the $\mathrm{HC}$ and $\mathrm{CO}$ emissions. For example, the fuel injection is split in two or three phases with short injection dwells. At medium loads, when HPC mode is used, early injection strategy allows near zero $\mathrm{NO}_{x}$ and particulate emissions but with a high noise level which is not compatible with the standard levels. Therefore, alternative injection strategies were investigated including late and split injections. At high loads, the engine is running with a conventional combustion mode and a quite conventional multi-injection strategy is applied.

\subsection{HPC Engine Control Challenges}

\subsubsection{Air Path Goals}

High EGR rate leads to more complex control compared to classical Diesel engine. As combustion characteristics under the condition of higher EGR rate are highly influenced by the amount of intake charge gas and its composition. It requires a precise control method to prevent the increase of $\mathrm{NO}_{x}$ and particulate matter in spite of the transient conditions of supercharging and tolerance of turbocharger. A key challenge is to control precisely the masses of fresh air and burned gases in the cylinder [7].

\subsubsection{Fuel Path Goals}

The necessity to deal with both conventional and HCCI combustion implies a different fuel injection strategy. The fuel control loop has to face transient in the same combustion mode and to be able to switch combustion mode at the same torque. The fuel loop dynamics is much faster than the air loop. It has to follow the air/EGR loop dynamics to both minimise pollutants and torque time response.

\subsection{NADI ${ }^{\mathrm{TM}}$ Engine Configuration}

\section{Supercharged air/EGR circuit}

In the NADI ${ }^{\mathrm{TM}}$ configuration, two air/EGR circuits can be used. A conventional air loop circuit with High Pressure EGR and a modified air loop circuit with a Low Pressure EGR. In this project the High Pressure EGR circuit has been used. Controlled by the EGR valve, burned gases are extracted upstream of the turbine, cooled by a cooling system and mixed with fresh air in the intake circuit, downstream the compressor. The air loop circuit has to be compatible with running conditions both at full load and at part load. At full load, the output torque and power specifications impose the air mass flow required by the engine according to the geometric compression ratio. At part load, the HPC mode needs high EGR mass flow. At medium loads, the demand of air and EGR increases and the compressor must supply sufficient air flow to ensure engine load with lambda value above 1.1, while high burned gas mass flow is needed for combustion control. We use a conventional single stage turbocharger with variable geometry turbine (VGT). When engine load increases in the HPC mode, intake EGR/fresh air mixture mass flow increases and requires high intake pressure which can make the compressor operate near the surge line at low engine speed. Small compressor size has therefore to be preferred. But future target standards for the maximum output power impose an adapted air mass flow leading to larger compressor size. So the compressor has to be compatible with high and low engine speeds. Compressor choice is helped by turbocharger development progress which leads to enlarged compressor maps. On the other hand, the weak exhaust gas energy available at the turbine inlet at low engine speed, which is further reduced by a high EGR rate, makes turbine efficiency a very important parameter to consider for the turbocharger choice. Because the EGR rate used in highly premixed combustion is significantly higher than in conventional combustion, advanced development of a specific cooler and valve is required both for the circuit permeability and for the fouling resistance optimization. EGR cooling system effectiveness is also an important parameter to be considered because of the high temperature burned gas mass flow used. Control of the burned gas temperature leads to better pollutant emission levels. By-passing partly the EGR cooler is in fact a simple way to modulate the burned gas temperature, already used on the production engine. 


\subsection{Experimental Set Up}

This paragraph aims to describe the engine hardware (represented in Fig. 1) used in terms of combustion chamber parts, compression ratio, turbocharger and type of EGR circuit. The multi-cylinder application is based on a production engine:

TABLE 1

Engine main characteristics.

\begin{tabular}{l|c}
\hline Bore x Stroke & $87.0 \times 92.0 \mathrm{~mm}$ \\
\hline Number of cylinders & 4 \\
\hline Displacement & 2.2 Liters \\
\hline Injection device & Solenoid \\
\hline Maximum injection pressure & 1600 bar \\
\hline Turbocharger & Variable Nozzle Turbine \\
\hline
\end{tabular}

As mentioned previously, the components of the combustion chamber were defined using single cylinder tests. The piston bowl was designed with the NADI ${ }^{\mathrm{TM}}$ bowl drawing specifications and the bowl volume was adapted to obtain a compression ratio of $14: 1$. The intake ducts of the cylinder head were modified in order to adapt the swirl motion to the required swirl number of 1.3 at BDC. All the results shown in this paper, including full load conditions, were obtained with the same swirl number, without any inlet duct closure. The injection system is with a maximum injection pressure of 1600 bar. The features of the injectors used are as follows:
- Spray cone angle: $60^{\circ}$

- Number of holes: 6

- Flow rate: $500 \mathrm{ml} / 30$ seconds / 100 bar.

The $\mathrm{NADI}^{\mathrm{TM}}$ application presented here is an engine equipped with only one turbocharger. The turbocharger was chosen in order to reach the power target fixed at full load. The turbocharger technology is conventional but the compressor and the turbine efficiency have been slightly improved compared to a production turbocharger. The air circuit includes an air cooler to maintain the temperature at $50^{\circ} \mathrm{C}$ in the intake manifold at full load.

A High Pressure EGR circuit was chosen for this application because of its short response time in transient operation for engine management development. This type of EGR circuit extracts burned gases in the exhaust manifold upstream of the turbine. The introduction of the exhaust gases is made downstream of the compressor, just upstream of the intake manifold, by means of a venturi to improve burned gases mixing with fresh air. The EGR circuit includes a cooler which is supplied by an external low temperature water circuit. The EGR cooler can be by-passed, which allows an increase of the intake temperature favorable to $\mathrm{HC}$ and $\mathrm{CO}$ emissions at very low engine loads. A well-adapted valve allows the EGR rate to be controlled. The high EGR mass flows used in the NADI ${ }^{\mathrm{TM}}$ concept, particularly at low engine load, requires a careful design of the EGR loop in order to maintain low level of pressure drop through the circuit.

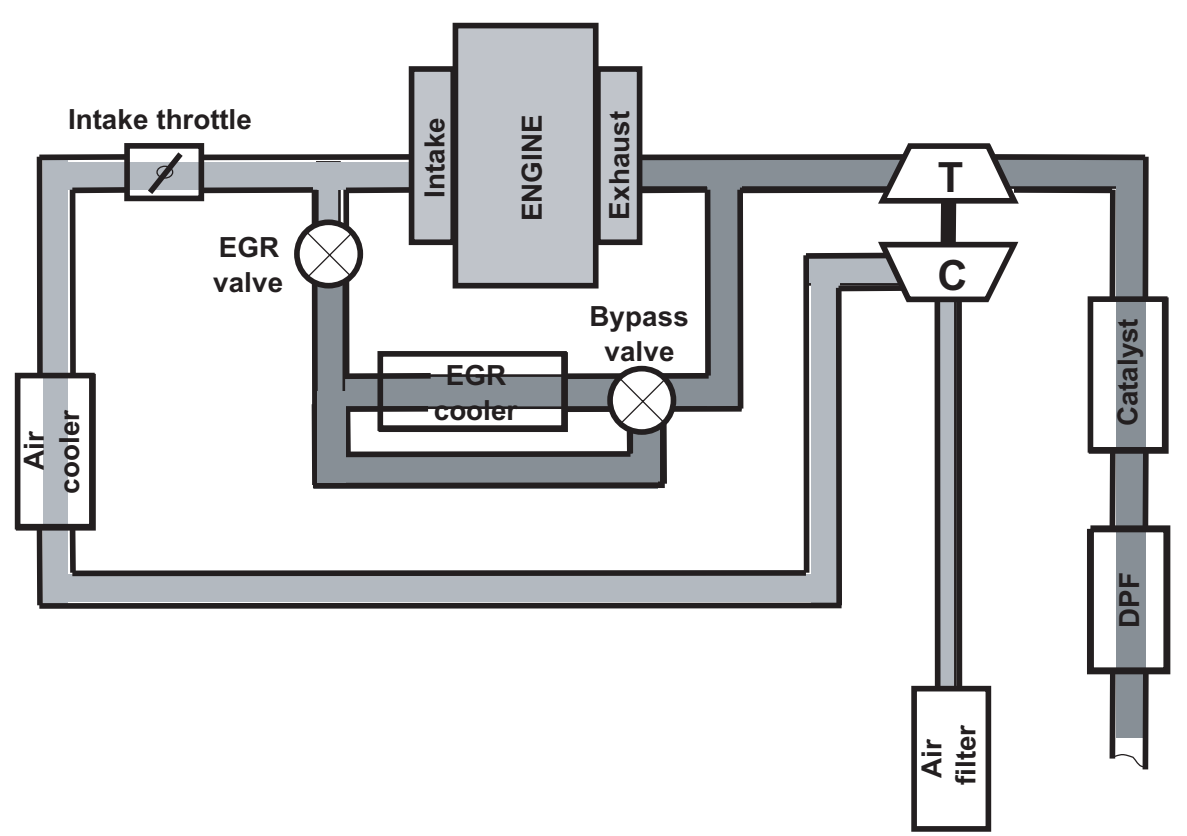

Figure 1

$\mathrm{NADI}^{\mathrm{TM}}$ engine architecture. 
A standard commercial gasoil with less than $50 \mathrm{ppm}$ sulphur content has been used.

\section{IFP TOOL CHAIN}

\subsection{Engine Modelling Approach}

Three main types of modelling level are used for engine simulation. The most accurate modelling approach is the CFD $2 \mathrm{D} / 3 \mathrm{D}$ simulation. It is dedicated to combustion chamber studies and permits detailed description of local phenomenon in the cylinder such as turbulent combustion and chemical kinetics. The characteristic timescale of CFD simulation is of the order of the turbulent timescale. At the present time, the CPU time of such a simulation only allows a few engine cycles to be run. The simplest modelling approach consists in representing the engine with operating condition look-up tables. This level allows CPU time lower than real time and is used to connect the engine with the whole powertrain and to run standard driving cycles with a vehicle simulator. The characteristic timescale of vehicle simulation is of the order of 0.1 second. At a turning point between these two approaches, the third modelling level is the engine system modelling. This approach involves phenomenological or empirical models and allows the complete engine with a characteristic timescale to be represented of the order of 0.1 crankshaft degree. Thanks to dedicated code optimization to limit the CPU time cost, the engine system model allows accurate reproduction of the behavior of the engine during transients such as driving cycles while reaching the real time in certain conditions. Therefore, this approach is especially adapted to be used as a support tool for engine control design from the control development to the hardware-in-the-loop validation [8].

\subsection{IFP-ENGINE Library}

The engine system simulation tool used for this study is the IFP-ENGINE library. It has been developed in the IMAGINE's numerical platform AMESim which is an open numerical environment for the modelling and simulation of dynamic systems inspired by Bond Graph approach. The numerical solver automatically and dynamically selects the best-adapted calculation method among 17 available algorithms. The computed gas consists of 3 species: fresh air, vaporized fuel and burned gas. Such a thermodynamic assumption has been identified as sufficient for engine performance results. Original developments have been achieved on engine combustion chamber modelling which is a crucial item for this kind of approach. Two phenomenological efficient models are available to represent gasoline [9] and Diesel combustion [10].

\subsection{HPC Diesel Engine Model}

The goal of engine system simulation is to supply the relevant model for the specific application. User expectations have to be accurately understood in order to achieve the optimum trade-off between physical description and calculation time cost. Engine control design has strong time cost constraints. It needs to perform a large amount of engine operating points and is oriented to real time environment. This model is running with a CPU time less than 20 times the real time with the variable time step solver and a $3 \mathrm{GHz}$ PC. The fixed time step solver can be used to reduce the CPU time, especially in order to build the real time engine model. Air path includes a compressor, pipes, a heat exchanger, a throttle and an intake manifold. All these elements are represented by dedicated submodels. The compromise required between the engine model accuracy and the simulation time cost has a major impact on the complexity of the phenomena taken into account in this part of the engine model. As representation of high frequency pulses in the intake manifold can be heavily time consuming, a trade-off between accuracy of instantaneous pressure fluctuations and time consumption is to be found. This is done by comparing different levels of manifold modelling details. For our purpose, the best compromise is the approach that allows the lowest time consumption while limiting the effect of in-manifold phenomena neglection on neighboring elements. The combustion chamber is connected to the air path through the cylinder head which acts thanks to valve lift laws and a permeability behavior model derived from experimental characterization. The fuel injection system allows up to three injections and control of each injection with the common rail pressure, the start of injection and the injection duration. In the cylinder wall, heat losses are modelled using a Woschni's approach with three independent temperatures for the cylinder head, the piston and the liner. The combustion heat release model is based on the conventional 0D Diesel combustion model approaches $[11,12]$ extended to multi-pulse injection, autoignition delay and EGR effect correction in order to get good combustion behavior in the whole range of operating set points, especially in both HPC and conventional combustion modes. A typical result is reported in Figure 2 (see [13] for more details). This model is a good representation of the main phenomena of the engine and is an excellent tool for control purposes.

\subsection{Rapid Prototyping System}

A rapid prototyping system was developed at IFP, thus enabling the study of the control strategies in parallel with the development of new engine technologies. This system had to be flexible, in order to facilitate the real time evaluation of new control strategies, but also had to be simple and robust 


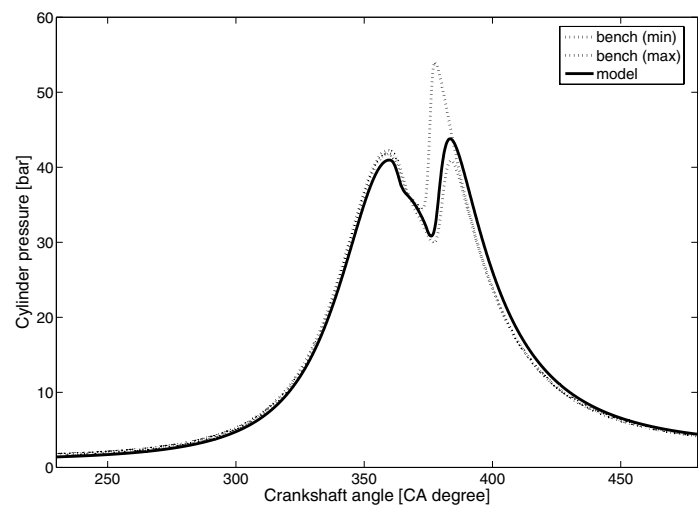

Figure 2

Model/Bench cylinder pressure comparison at IMEP $=6$ bar $(\mathrm{EGR}=35 \%)$

to be able control of an engine during a characterization campaign.

A system based on the Mathworks tool-chain was chosen for the flexibility of Simulink, RTW, and XPC target for cost reasons compared to dSpace. The control strategies are developed under Simulink, tested and validated offline on AMESim models, then compiled and executed in real time on a PC operating with XPC target. This system was to be used for diesel and gasoline engines from 1 to 8 cylinders, and therefore had to be capable of generating pulses synchronized to crank angle. A specific PCI timer board was developed for these purposes.

The timer board is capable of generating interruptions to the PC, so that it is possible to synchronise the execution of some algorithms with the engine. This can be used to phase computations or measurements with the engine top dead centre (injection, EGR valve set-point, ... ), or at any engine frequency. For example, some computations are made every six degrees crank angle, frequency corresponding to the conventional engine encoder with fifty eight teeth and thus producing results representative of what can be achieved with a production ECU.

The final system comprises (see Fig. 3):

- A supervisor PC, enabling the real time modification and visualisation of parameters.

- A real time PC, executing the code generated from a Simulink model, including I/O boards, and a PCI timer board, ensuring the synchronisation with the engine angular encoder, and the commands of the actuators (generation of engine synchronized pulses, of PWM signals, ...).

- Some signal conditioning hardware for the interface between the I/O boards and the sensors / actuators.

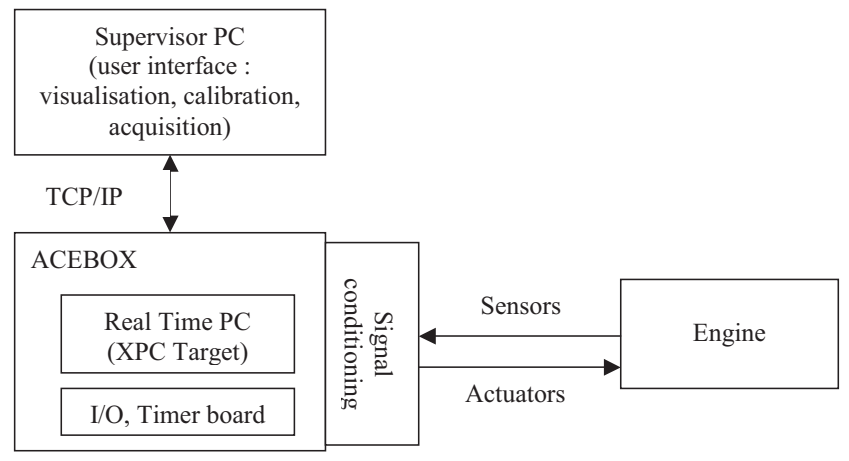

Figure 3

Final system structure.

\section{INDIVIDUAL TORQUE ESTIMATION}

The combustion torque characterizes the performance of the engine and is the result of various inputs such as injection quantity and timing, EGR rate.... Ideally this torque could be measured using fast pressure sensors in each cylinder. Unfortunately, high cost and low reliability prevent these sensors from reaching commercial products. As a consequence, we need to design real-time observers for the combustion torque using the reliable and available instantaneous engine speed as the only measurement.

Combustion torque determination by the measurement of the instantaneous engine speed has been addressed previously in the literature. Most of the proposed solutions have their foundation on a Direct or Indirect Fourier Transform for a black box model (see [14], [15], [16]). Others focus on a stochastic approach (see [17]) but the problem of realtime estimation is not addressed. Other approaches such as mean indicated torque are also proposed (see [18] and [19] for example). Solving this first problem opens the door to more exciting applications such as misfiring detection ([20] and [21]) and combustion analysis.

\subsection{Crankshaft Dynamics}

In this part, we briefly describe the dynamics of the system stressing out the role of the combustion torque, $T_{\text {comb }}$, also referred to as the indicated torque. Following [22], the torque balance on the crankshaft can be written

$$
T_{\text {comb }}-T_{\text {mass }}-T_{\text {load }}^{*}=0
$$

where $T_{\text {load }}^{*}=T_{\text {load }}+T_{\text {fric }}$ is referred to as "the extended load torque" and $T_{\text {load }}$ (the load torque) and $T_{\text {fric }}$ (the friction torque) are known. The mass torque $T_{\text {mass }}$ is the derivative of the kinetic energy $E_{\text {mass }}$ of the moving masses in the engine 

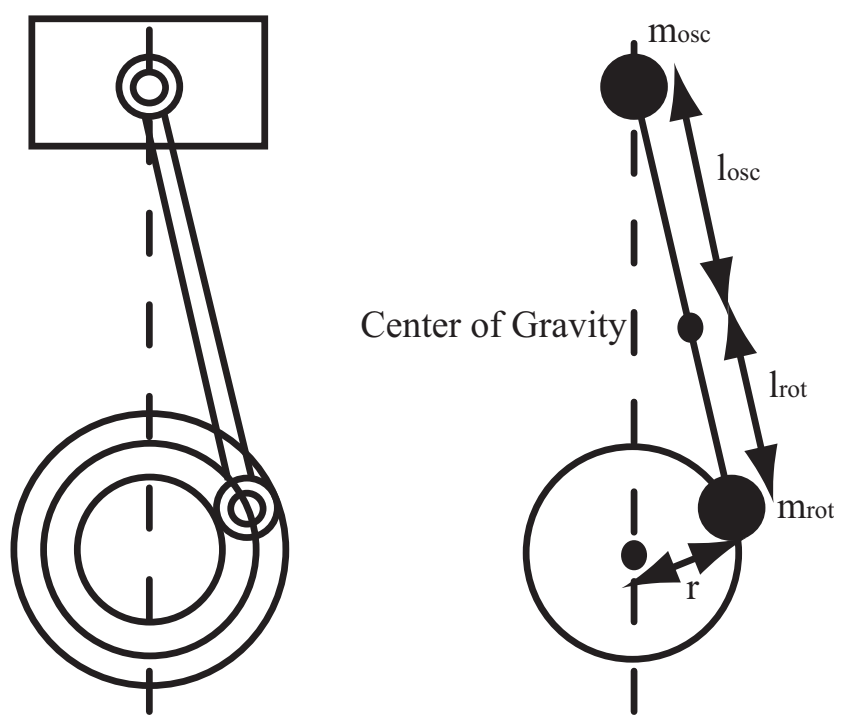

Figure 4

Mass Model.

as described in Figure 4.

$$
E_{\text {mass }}=\int_{0}^{2 \pi} T_{\text {mass }} d \alpha=\frac{1}{2} J(\alpha) \dot{\alpha}^{2}
$$

where $\alpha$ is the crank angle. The mass torque $T_{\text {mass }}$ can be expressed as

$$
\frac{d E_{\text {mass }}}{d t}=T_{\text {mass }} \dot{\alpha}
$$

The computation of the various elements of $J$ are described in [23] and are usually perfectly known for a particular engine. $J(\alpha)$ is a periodic function in $\alpha$ over an engine cycle.

\subsection{Reference Model}

In this part, we propose to decompose the mass torque on a Fourier basis and make an adaptation of the coefficients. This observation technique is explained in a continuous time framework and then will be implemented in a discrete time version of it which is more appropriate to real-time application.

An energy balance yields

$$
\frac{d}{d \alpha}\left(\frac{1}{2} J(\alpha) \dot{\alpha}^{2}\right)=T_{\text {mass }}(\alpha)
$$

$T_{\text {mass }}(\alpha)$ is $4 \pi$-periodic, we can decompose it on a Fourier basis. Keeping the $n_{h}$ first harmonics, we get the approximation:

$$
T_{\text {mass }}(\alpha) \simeq a_{0}+\sum_{i=1}^{n_{h}}\left(a_{i} \cos \left(i \frac{\alpha}{2}\right)+b_{i} \sin \left(i \frac{\alpha}{2}\right)\right)
$$

The dynamics reads

$$
\frac{d \phi}{d \alpha}=a_{0}+\sum_{i=1}^{n_{h}}\left(a_{i} \cos \left(i \frac{\alpha}{2}\right)+b_{i} \sin \left(i \frac{\alpha}{2}\right)\right)
$$

where $\phi(\alpha)=E_{\text {mass }}=\frac{1}{2} J(\alpha) \dot{\alpha}^{2}$ is the kinetic energy of the system.

We have a $4 \pi$-periodic state-space model. The engine speed $\dot{\alpha}^{2}$ is the output and is referred to as $y$.

$$
\begin{cases}\frac{d x}{d \alpha} & =\mathcal{M}(\alpha) x \\ y & =C(\alpha) x\end{cases}
$$

with

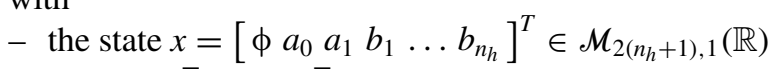

$$
\begin{aligned}
& \text { - } \mathcal{M}(\alpha)=\left[\begin{array}{cc}
0 & M(\alpha) \\
0 & 0 \\
\vdots & \vdots \\
0 & 0
\end{array}\right] \in \mathcal{M}_{2\left(n_{h}+1\right), 2\left(n_{h}+1\right)}(\mathbb{R}) \\
& \text { - } M(\alpha)=\left[1 \cos \left(\frac{\alpha}{2}\right) \ldots \sin \left(n_{h} \frac{\alpha}{2}\right)\right] \in \mathcal{M}_{1,2 n_{h}+1}(\mathbb{R}) \\
& \text { - the observation matrix } \\
& C=\frac{2}{J(\alpha)}\left[\begin{array}{llll}
1 & 0 & \ldots & 0
\end{array}\right] \in \mathcal{M}_{1,2\left(n_{h}+1\right)}(\mathbb{R})
\end{aligned}
$$

\section{Observer Definition}

With this state-space model, we define a time-varying observer. The observer dynamics are:

$$
\begin{cases}\frac{d \hat{x}}{d \alpha} & =\mathcal{M}(\alpha) \hat{x}-\mathcal{L}(\alpha)(\hat{y}-y) \\ \hat{y} & =C(\alpha) \hat{x}\end{cases}
$$

with

$$
\mathcal{L}(\alpha)=\frac{J(\alpha)}{2}\left[\begin{array}{c}
L_{k e} \\
L_{a_{0}} \\
L_{a_{1}} \cos \left(\frac{\alpha}{2}\right) \\
L_{b_{1}} \sin \left(\frac{\alpha}{2}\right) \\
\vdots \\
L_{a_{n_{h}}} \cos \left(n_{h} \frac{\alpha}{2}\right) \\
L_{b_{n_{h}}} \sin \left(n_{h} \frac{\alpha}{2}\right)
\end{array}\right] \in \mathcal{M}_{2\left(n_{h}+1\right), 1}(\mathbb{R})
$$

where $L_{k e}$ refers to the strictly positive gain on the kinetic energy, while $L_{a_{0}}, \ldots, L_{b_{n h}}$ are the strictly positive gains for the Fourier basis coefficients. For the sake of simplicity we change notations through the following reordering. We define $\left\{f_{k}\right\}_{k \in\left\{0,2 n_{h}\right\}}$ such that

$$
\begin{aligned}
f_{0}(\alpha) & =1 \\
f_{2 i-1}(\alpha) & =\cos \left(i \frac{\alpha}{2}\right) \\
f_{2 i}(\alpha) & =\sin \left(i \frac{\alpha}{2}\right)
\end{aligned}
$$


and the strictly positive constants $\left\{l_{k}\right\}_{k \in\left[0,2 n_{h}\right]}$ such that

$$
\begin{aligned}
l_{0} & =L_{a_{0}} \\
l_{2 i-1} & =L_{a_{i}} \\
l_{2 i} & =L_{b_{i}}
\end{aligned}
$$

We have

$$
\mathcal{L}(\alpha)=\frac{J(\alpha)}{2}\left[\begin{array}{c}
L_{k e} \\
l_{0} f_{0}(\alpha) \\
l_{1} f_{1}(\alpha) \\
\vdots \\
l_{2 n_{h}} f_{2 n_{h}}(\alpha)
\end{array}\right] \in \mathcal{M}_{2\left(n_{h}+1\right), 1}(\mathbb{R})
$$

Convergence of such an observer is proven in [24].

\subsection{Simulation Results}

\subsubsection{Choice of the Number of Harmonics}

In all the previous section, we use a general parameter $n_{h}$ corresponding to the number of harmonics used to reconstruct the signal. The number of harmonics must be large enough to estimate the signal, but on the other hand the more harmonics we have, the more tedious the tuning phase is. Figure 5 shows reconstructed harmonics expansions using various number of harmonics $n_{h}$. We see that we need at least five harmonics to represent the signal well.

\subsubsection{Observer Tuning}

Without any methodology, the tuning of the parameters of the observer is tricky. We have $n_{h}+2$ parameters to tune

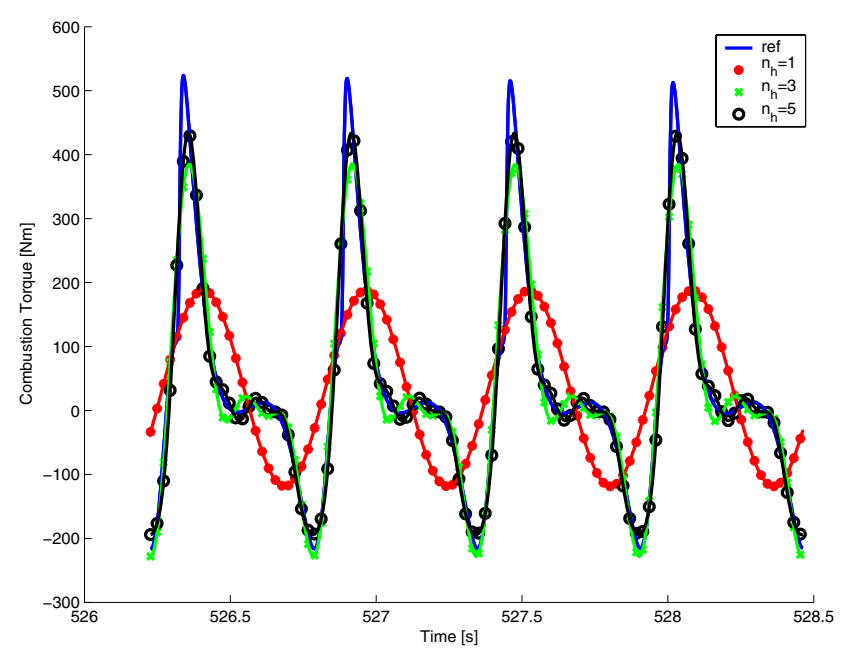

Figure 5

Decomposition of the mass torque $T_{\text {mass }}(1500 \mathrm{rpm}, 2 \mathrm{bar}$ ), comparisons between the reference signal and its reconstructed version through harmonic expansion. (as there is apparently no reason to differentiate the cos and the sin terms for the same frequency). Here, we propose a methodology that leads to the tuning of only three parameters whatever the choice of $n_{h}$. We choose $L_{a_{i}} \triangleq L_{b_{i}} \triangleq i L_{r e f}$. We still have three parameters to pick $\left(L_{k e}, L_{a_{0}}\right.$ and $\left.L_{r e f}\right)$. $L_{k e}$ is the $\dot{\alpha}^{2}$ feedback term and is chosen with respect to the expected noise on the instantaneous engine speed $\dot{\alpha}$ measurement. $L_{a_{0}}$ is the feedback term that assures convergence of the constant term in the harmonics expression. It is chosen with respect to the desired speed of convergence compared to the engine speed.

$$
L_{r e f}<\frac{2}{n_{h}\left(n_{h}-1\right)}\left(\frac{2}{\Delta \alpha} L_{k e}-L_{a_{0}}\right)
$$

Nevertheless, the choice of $L_{k e}$ is difficult since it is the compromise between precision and robustness. With this choice of parametrization, convergence is guaranteed.

\subsubsection{Simulation Results}

We present a simulation corresponding to a set point:

- Engine Speed: $1000 \mathrm{rpm}$

- BMEP: 5 bar

To simulate the unbalance, we introduce offsets in the mass injected in each cylinder.

- Cylinder 1: $10 \%$ of the reference mass

- Cylinder 2: $0 \%$ of the reference mass

- Cylinder 3: 0\% of the reference mass

- Cylinder 4: $-20 \%$ of the reference mass

In Figure 6 the setpoint is a low engine speed and a low load. This point is very interesting because it represents where the driver feels vibrations most. Correcting the unbalance at this points increases the driver's comfort.

\subsection{Experimental Results}

Figure 7 displays the result of the estimator on experimental data. We reconstruct the combustion torque from the bench with the in-cylinder pressure and we test the observer on the flywheel velocity measurement. The setpoints are not the same as the simulation one.

The decomposition of the Fourier basis seems to be relevant on this application. Even if the number of harmonics needed to recompose the signal is high (5 in the presented results), a simple methodology allows us to reduce the number of parameters to tune to only three. In practice though, the bottleneck is the low sampling rate. When few samples are available during a cycle (typically 120), adaptation of the coefficients can become problematic. This imposes an upper limitation on the number of harmonics. Moreover, this method is very sensitive to the noise on the $6^{\circ}$ measurement (due to the imperfection of the flywheel and the angular encoder). This noise is twofold: classic noise 


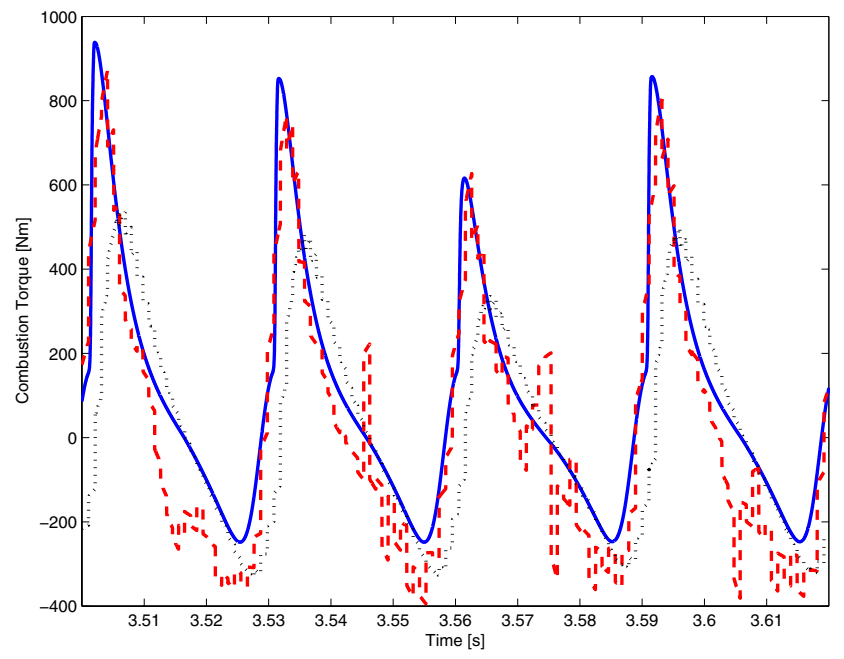

Figure 6

Combustion torque on simulation $(1000 \mathrm{rpm}, 5$ bar). bold (blue): reference combustion torque, dashed (red): combustion torque estimated by the the presented filter, dotted (black): combustion torque estimated by pole placement as in [25].

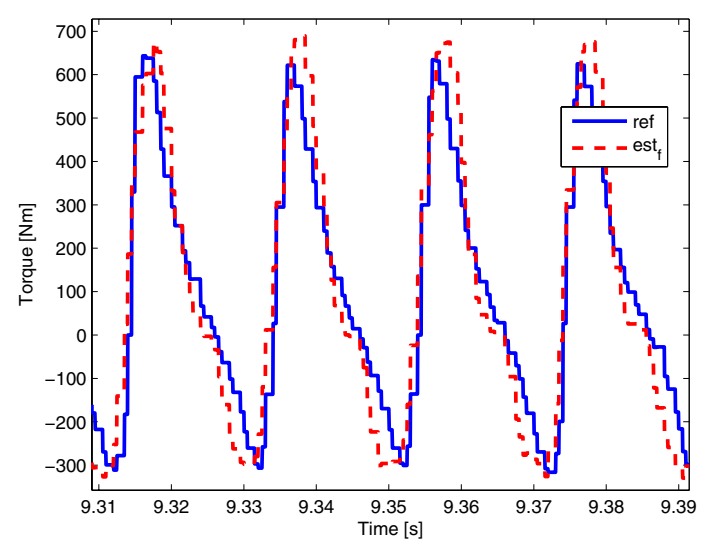

Figure 7

Combustion torque on the test bench. bold (blue): reference combustion torque, dashed (red): combustion torque estimated by the presented filter.

on the value of the engine speed and inaccurate synchronization on the $6^{\circ}$ flywheel. The harmonic decomposition of the signal assumes perfect periodicity of the instantaneous engine speed signal and yields erroneous adaptation when synchronization noise on the angle is present (unlikely in practice, since the encoder is high quality and based either on optical or mechanical technology). As usual there is a tradeoff between the required accuracy and the noise on the measurements.

In Figure 6 results from simulation are given. The overall shape of the signal is well reconstructed. No phase shift is present (by contrast the pole placement observer has a $18^{\circ}$ phase shift). The maxima are accurate, in fact the obtained values almost reach the values of the off-line best harmonic approximation in Figure 5. Noise is present on the lower part of the signals. It is due to the previously exposed issue. In the simulator there is a mismatch between the time-samples and the angular samples. This mismatch is particularly important when the angular speed reaches its maximum. This is the case when the torque reaches zero. This phenomenon can be avoided by reducing the time sample, but we found it illustrative not to do so, since in practice such errors are representative of encoders noise. In the presented simulations the time-sample is $10 \mu \mathrm{s}$ which corresponds (with fluctuations due to the variable engine speed) to $1 / 100$ of the angular step.

In Figure 7 results from the test bench are given. The same observer is used. Results are satisfactory. The noise on the test bench signal induces errors that are different from the simulated ones. More precisely, maxima are over estimated, but their relative values are consistent. Noise at the maximum of the engine speed is still present but attenuated. Most importantly no phase shift is induced.

The results of the presented adaptive Fourier basis decomposition observer are good. As is, robustness of the observer with respect to engine speed noises is satisfactory but could be improved further. This is not an easy problem though, since filtering of the input signals could help, but phase shifts are not acceptable.

In the context of combustion real-time control, this observer is a handy tool. It does not suffer from any phase shift, and can thus be used in a closed loop controller of the fuel injectors. This is the long term goal of our work.

Moreover this observer is easily transposable to various engine speeds and loads. Its dynamics are expressed in angular time scale and do not require any model for the combustion process. Theoretically, the gains do not need to be updated when the set-point is changed. However, due to the encoder structure, noise is not completely set-point independent, so in practice some re-tuning is required.

\section{INDIVIDUAL AFR ESTIMATION}

An other important step toward the combustion control is the Air Fuel Ratio (AFR) control and estimation. It results from various inputs such as injected quantities, exhaust gas recirculation (EGR) rate and boost pressure. Classically, in Spark Ignition engine, overall AFR is directly controlled with the injection system. In this approach, all cylinders share the same closed-loop input signal based on the single $\lambda$-sensor (normalized Fuel-Air Ratio measurement, it can be rewritten with the total and air masses in the exhaust manifold as $\lambda \triangleq 1-\frac{M_{\text {air }}}{M_{T}}$ ). Ideally, all the cylinders would have the same AFR as they have the same injection set-point. Unfortunately, due to inherent flaws of the injection system (pressure waves, mechanical tolerances, ...), the total mass of 


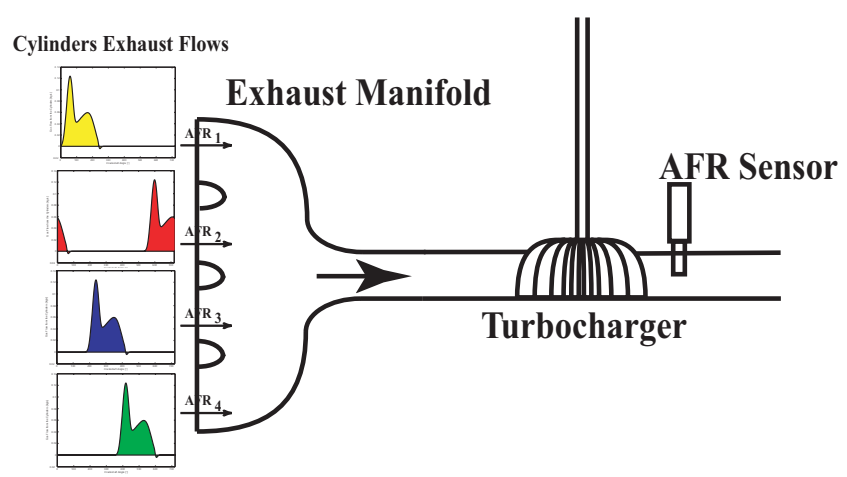

Figure 8

Exhaust dynamics: Individual Air Fuel Ratio problem.

fuel injected in each cylinder is very difficult to predict with a relative precision below 7\%. Individual cylinder control has been addressed using individual cylinder $\lambda$-sensors in [27] which is not realistic in the context of this study.

In previous works (see [28] and [29]), the methods used to reconstruct the AFR of each cylinder from the UEGO (Universal Exhaust Gas Oxygen) $\lambda$-sensor measurement are based on the permutation dynamics at the TDC (Top-Dead Center) time-scale and a gain identification technique. Here we propose a higher frequency approach $\left(6^{\circ}\right.$ degree crankshaft angle modelling and update instead of $180^{\circ}$ (TDC)). All cylinders share the same closed loop input signal based on the single $\lambda$-sensor. This results in unbalance in the exhaust gases. Figure 8 shows the flow sheet of individual AFR from the cylinders outlet down to the turbine. From the cylinders to the $\lambda$-sensor (located downstream the turbine), the gases travel through the exhaust pipes, the exhaust manifold, and the turbocharger. All these components have an influence on the gas pressure, temperature, and composition in the exhaust manifold. In a very naive model, the gases move at constant speed, without mixing. In practice, diffusion and mixing effects are present. We propose a nonlinear model to take these into account. Our approach focuses on macroscopic balances involving experimentally derived nonlinear functions.

\subsection{Mass Balance in the Exhaust Manifold}

Balance equations (6) and (7) and fixed operating conditions (8) yield

$$
\begin{aligned}
\frac{d M_{T}}{d \alpha} & =f_{1, \Xi}\left(M_{T}, \alpha\right) \\
\frac{d M_{\text {air }}}{d \alpha} & =f_{2, \Xi}\left(M_{T}, M_{\text {air }},\left\{\lambda_{i}\right\}_{i \in\left[1, n_{c y l}\right]}, \alpha\right) \\
\frac{d \lambda_{i}}{d \alpha} & =0, \quad \forall i \in\left[1, n_{c y l}\right]
\end{aligned}
$$

where

$$
f_{1, \Xi}\left(M_{T}, \alpha\right)=-\frac{1}{N_{e}} d_{T}\left(M_{T}, \Xi\right)+\frac{1}{N_{e}} \sum_{i=1}^{n_{c y l}} d_{i}(\alpha, \Xi)
$$

and

$$
\begin{aligned}
f_{2, \Xi}\left(M_{T}, M_{a i r},\left\{\lambda_{i}\right\}_{i \in\left[1, n_{c y l}\right]}, \alpha\right)= & -\frac{1}{N_{e}} \frac{M_{a i r}}{M_{T}} d_{T}\left(M_{T}, \Xi\right) \\
& +\frac{1}{N_{e}} \sum_{i=1}^{n_{c y l}}\left(1-\lambda_{i}\right) d_{i}(\alpha, \Xi)
\end{aligned}
$$

Operating conditions are defined by the $\Xi$ parameters (mean aspirated flow $D_{a s p}$, exhaust temperature $T_{e x h}$, turbocharger speed $\left.N_{\text {turbo }}\right)$. They are assumed constant over an engine cycle.

The $T_{0}$-periodic $d_{i}(., \Xi)$ functions are modelled through interpolation of a large number of available data. The functions family $\left\{d_{i}\right\}_{i=1 \ldots n_{c y l}}$ is a linearly independent family of the set of continuous $T_{0}$-periodic functions. Figure 9 shows such a flow at $1500 \mathrm{rpm}$ and 11 bar of IMEP.

The flow rate through the turbine $d_{T}$ is a function of the total mass $M_{T}$ and can be factorized as

$$
d_{T}\left(M_{T}, \Xi\right)=p\left(M_{T}, \Xi\right) M_{T}
$$

with for a given operating condition, $p$ a positive increasing (concave) function with respect to the total mass $M_{T}, e . g$. $p(z, \Xi)=p_{0}(\Xi) \sqrt{2 \frac{\gamma}{\gamma-1}\left(\left(\frac{z}{z_{0}}\right)^{-\frac{2}{\gamma}}-\left(\frac{z}{z_{0}}\right)^{-\frac{\gamma+1}{\gamma}}\right)}$. Usually given by a 2D look up table as in Figure 10, the flow rate is modelled as a flow through a restriction [30] with a variable section depending on the pressure ratio and the turbocharger speed (as proposed in [31] and [32]). Composition of the flow through the turbine and in the exhaust manifold are equal.

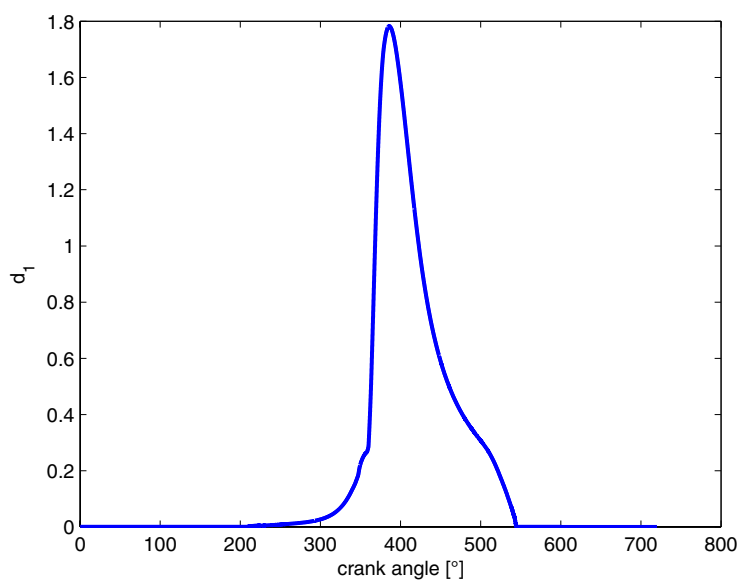

Figure 9

Experimental input flows from cylinder 1 at $1500 \mathrm{rpm}$ and 11 bar of IMEP over one cycle. 


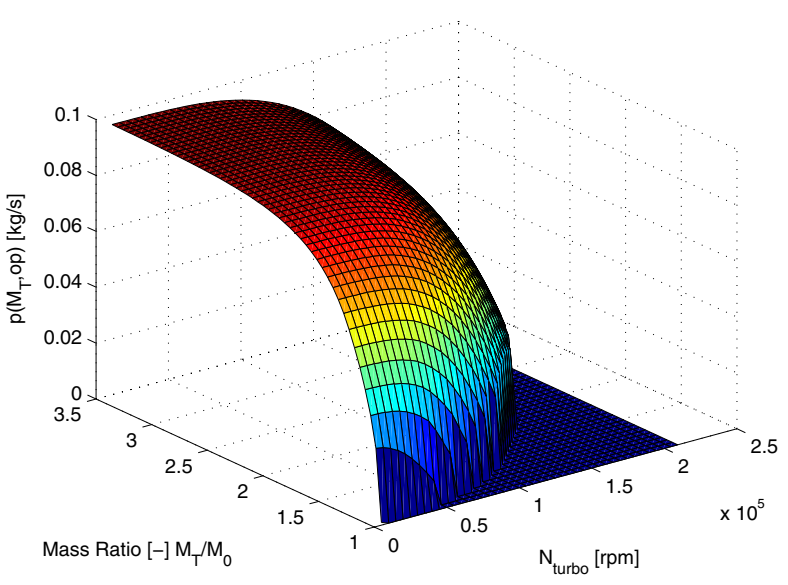

Figure 10

Flow rate through the turbine as a function of turbocharger speed and mass ratio.

\subsection{Measurements}

At first, two sensors are considered for our observer design, although extra sensors are available on a prototype engine to ensure performance analysis. The measurements are:

- $P$, the pressure in the exhaust manifold, assumed to be related to the total mass by $P=\gamma_{T} M_{T}$. In this work, the exhaust pressure sensor can be substituted with an open loop model. The reason for this choice is to propose a versatile observer, able to work with or without an exhaust pressure sensor, usually not available on commercial engine.

- $\lambda$ the normalized Fuel-Air Ratio measurement. It can be rewritten without with the total and air masses in the exhaust manifold as $\lambda \triangleq 1-\frac{M_{\text {air }}}{M_{T}}$.

The first observer we present here involves the nonlinear dynamics (6)-(7)-(8) and nonlinear tracking terms with 3 constants gains.

\subsection{Observer Definition}

Let $x=\left[\begin{array}{llll}M_{T} & M_{\text {air }} & \lambda_{1} \ldots \lambda_{n_{c y l}}\end{array}\right]^{T} \in \mathbb{R}^{n_{c y l}+2}$ be the state and $y=[P \lambda]^{T} \in \mathbb{R}^{2}$ the measurements. The observer dynamics are

$$
\left\{\begin{aligned}
\frac{d \hat{x}_{1}}{d \alpha}= & f_{1}\left(\frac{1}{\gamma_{T}} y_{1}, \alpha\right)+\frac{L_{1}}{N_{e}}\left(\frac{y_{1}}{\gamma_{T}}-\hat{x}_{1}\right) \\
= & f_{2}\left(\frac{1}{\gamma_{2}} y_{1},\left(1-y_{2}\right) \frac{1}{\gamma_{T}} y_{1}, \hat{x}_{2+i}, \alpha\right) \\
& +\frac{L_{2}}{N_{e}}\left(\left(1-y_{2}\right) \frac{1}{\gamma_{T}} y_{1}-\hat{x}_{2}\right) \\
\frac{d \hat{x}_{2+i}}{d \alpha}= & -\frac{L_{\lambda}}{N_{e}} d_{i}(\alpha)\left(\left(1-y_{2}\right) \frac{1}{\gamma_{T}} y_{1}-\hat{x}_{2}\right)
\end{aligned}\right.
$$

where last equation holds for all $\mathrm{i} \in\left[1, n_{c y l}\right]$, and where $\left(L_{1}, L_{2}, L_{\lambda}\right) \in\left(\mathbb{R}^{+} \backslash\{0\}\right)^{3}$. Convergence of this observer can be found in $[33,34]$.

\subsection{Tests Setup}

The estimator described above is tested in simulation on the presented simulator. On both simulation and experimental testbench, we apply an injection duration timing trajectory to introduce unbalance. It produces offsets in injection which lead to AFR disturbances. More precisely the injection steps have an effect on the average level of the measured AFR and introduce oscillations of the overall AFR signal as represented in Figure 11. These oscillations are the direct consequences of the individual AFR differences. During cylinder 1 exhaust phase, the AFR increases in the manifold, and then decreases while the other cylinders' exhaust phases occur. The magnitude of the oscillations is related to the amount of the AFR difference between the cylinders and the gas mass in the manifold (and thus to its volume). The oscillation is then propagated to the turbine, and to the UEGO sensor, where it is filtered. This is the information that we exploit in the nonlinear observer (9).

\subsection{Simulation Results}

Figure 12 presents results from simulation on the trajectory reference. The results are both quantitatively and qualitatively accurate. We reproduce well the evolution of the AFR. In practice the convergence is achieved within 4 engine cycles. The real bottleneck is the sensor noise and the quality of its model. In our results a simple first order model was used and seems relevant for this application. However, as rpm increases, better approximations would be useful. These results are encouraging for control purposes.

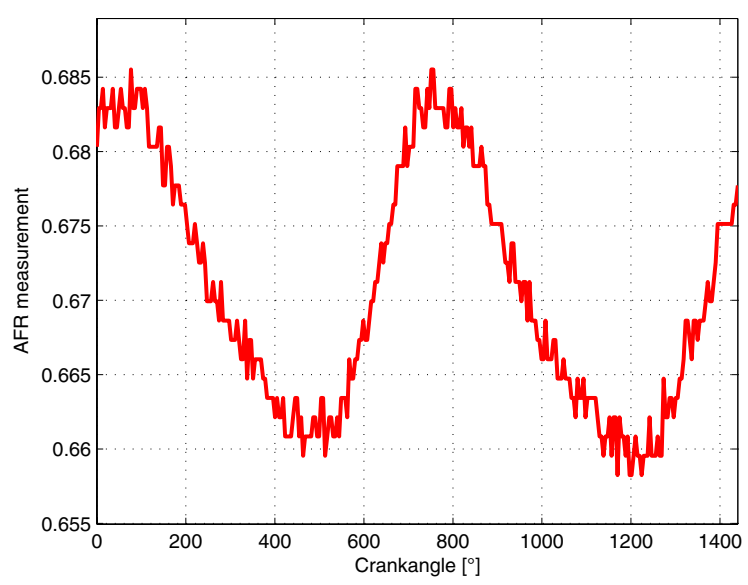

Figure 11

AFR measurement oscillations over 2 engine cycle during a $+20 \%$ offset on cylinder 1 . 

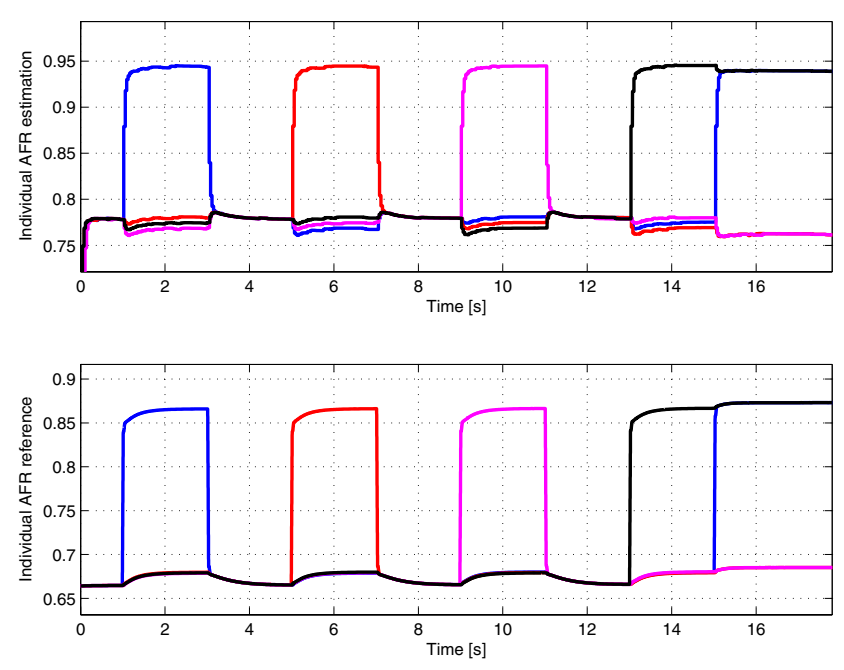

Figure 12

Trajectory on simulation at $3500 \mathrm{rpm}$ and $800 \mu \mathrm{s}$ using the trajectory injection offset. Top: Reconstructed with (9). Bottom: Actual values from simulation

\subsection{From Simulation to Experiment}

On the test bench we use both proposed observers according to the scheme in Figure 13. Several practical issues are considered. We now detail these.

\section{Observers implementation}

Block (A) is the implementation of the individual AFR observer.

\section{Open loop pressure model}

Exhaust pressure sensor can be expected for forthcoming HCCI vehicles only. In experimentation, we consider not having this sensor and assign an open loop value to the estimator. This value is given by the open loop balance with the input flows $\left(d_{i}\right)$ and output flow $d_{T}$ as described previously in Subsection 4.1. This model is implemented in Block (B) in Figure 13.

\section{Gas transport delay}

Lags due to gas transport along the engine exhaust (pipes and dead volumes), and the dead time of the sensor are not represented by the model described above in System (6)(7)-(8). Delays can be lumped into a single delay for the complete exhaust system, and the model can be inverted. This delay can be identified and kept as a constant for a given setpoint on the (engine speed, load) map. This estimation is implemented in Block (C) in Figure 13.

\section{AFR Sensor Inversion}

The AFR sensor has a low-pass transfer function. Sampling noise is filtered by a very high frequency low-pass filter. The

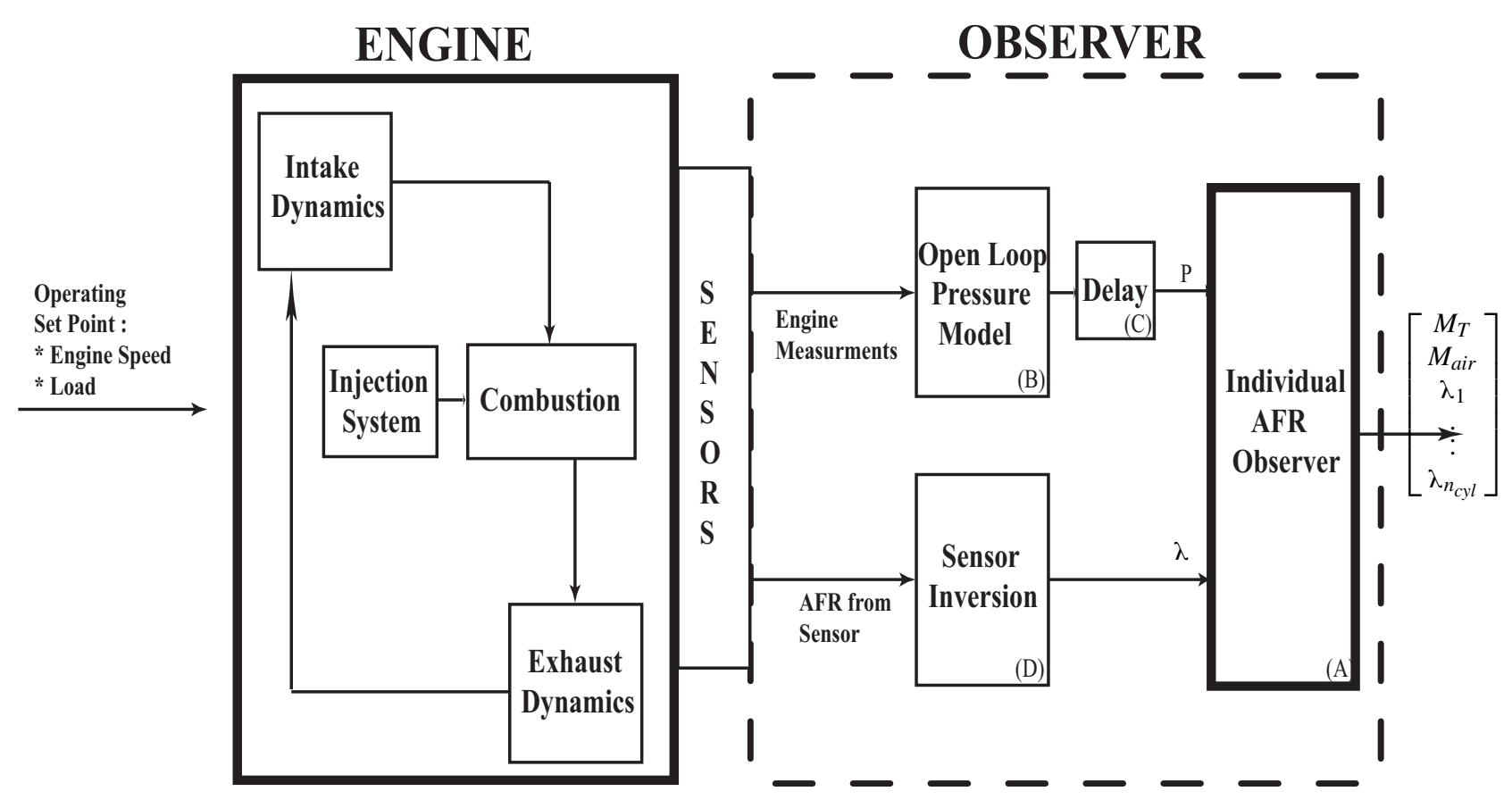

Figure 13

Engine and observer connection. 
sensor dynamics can be approximated by a second order filter. In order to robustly invert dynamics of the sensor, we apply an observer based on an adaptive Fourier decomposition (Block (D) in Figure 13), see [35] for more details.

\subsection{Experimental AFR Imbalance}

To introduce unbalance on the experimental testbench, we apply an injection duration timing trajectory as mentioned above. Offsets introduce oscillations as represented in Figure 11. These oscillations are the direct consequences of the individual AFR unbalance. The same tuning parameters are kept from simulation to experimentation. Further, a single set of tuning parameters is kept over all the operating points.

Actual AFR are not directly available but can be correlated on the experimental engine to the torque produced by each cylinder (reconstructed from the experimental individual incylinder pressure sensors through $T_{\text {mass }}=\int P d V$ ). These correlated values, noted $\lambda_{\text {ref }}$, serve as reference for comparisons.

\subsection{Experimental Results}

Experimental results are reported in Figures 14 and 15.

Results are quantitatively and qualitatively accurate. We reproduce well the evolution of the AFR. In practice the convergence is achieved within 4 engine cycles. In all test bench cases, we were able to predict the individual cylinder AFR well. Further, we can easily detect the AFR unbalance and have a good estimation of the peaks of the AFR disturbances. The magnitude of the individual AFR offsets are satisfactory. Results are better at mid to high load (over 6 bar of IMEP). This comes from the model of a
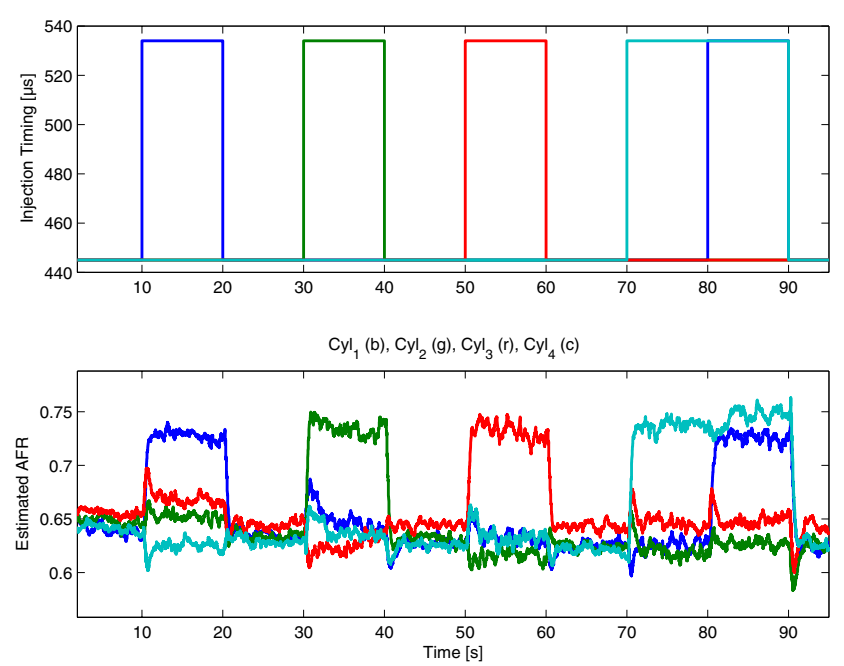

Figure 14

Test bench nonlinear observer results (engine speed $1500 \mathrm{rpm}$, IMEP 9 bar). Top: main injection duration $[\mu s]$. Bottom: individual estimated AFR.
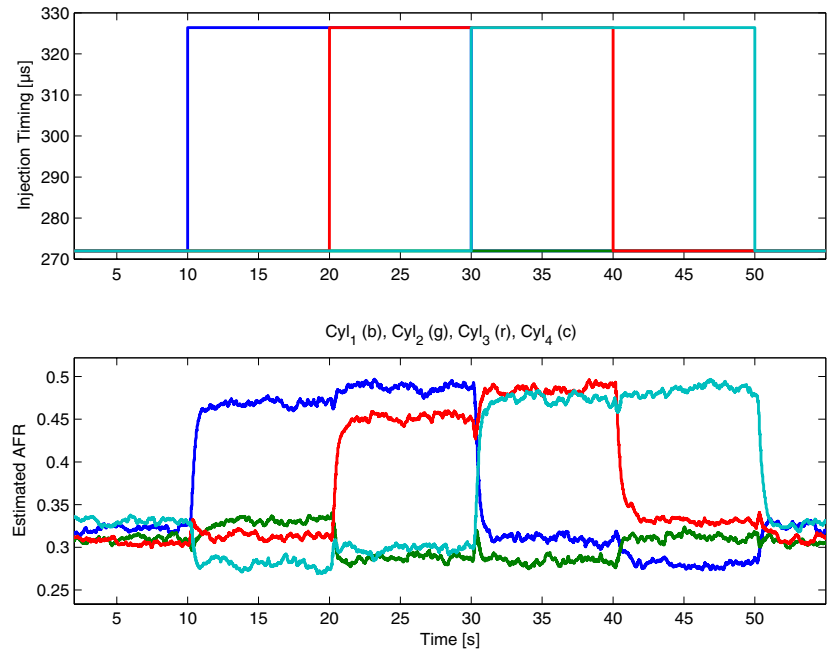

Figure 15

Test bench nonlinear observer results (engine speed $1500 \mathrm{rpm}$, IMEP 6 bar). Top: main injection duration $[\mu s]$. Bottom: individual estimated AFR.

variable geometry turbocharger which is better at these loads. Indeed, at low load, the turbocharger is almost not activated $\left(N_{\text {turbo }}<25000 \mathrm{rpm}\right)$ and our model is not very accurate in this operating condition due to friction on the turbocharger. At higher load, the turbocharger is in action and the model of flow through the turbine is much more accurate and leads to very good results. Nevertheless, measurement noise is not setpoint independent, in fact sampling errors affect the results for high rpm.

\subsection{Computation Requirement}

Computation times of each element in Figure 13 required for observer implementation are reported in Table 2.

TABLE 2

Table of computation time of each block.

\begin{tabular}{l|c}
\hline $\begin{array}{c}\text { Block A: Individual AFR Estimation } \\
\text { Nonlinear observer }\end{array}$ & $2.70 \mu \mathrm{s}$ \\
\hline Block B: Exhaust dynamics model & $6.70 \mu \mathrm{s}$ \\
\hline Block C: Delay & $<0.05 \mu \mathrm{s}$ \\
\hline Block D: AFR sensor dynamics inversion & $6.35 \mu \mathrm{s}$ \\
\hline
\end{tabular}

\section{CONCLUSION: TOWARDS INDIVIDUAL CYLINDER CONTROL}

The availability of estimators described here, giving reliable information, can lead to improvements on diesel engines in terms of combustion control, noise, and pollutant emissions. 


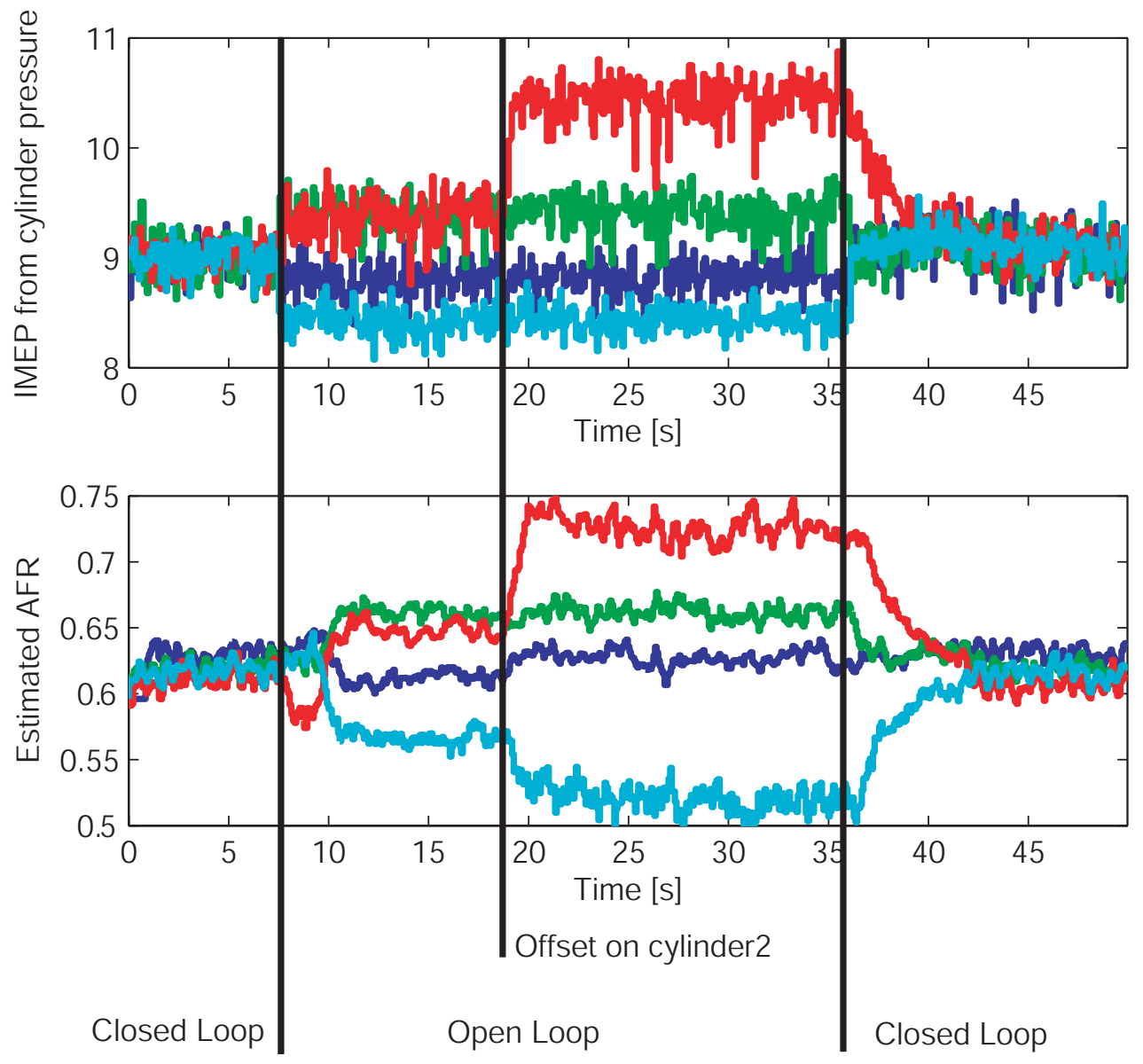

Figure 16

Torque balancing based on individual AFR estimation: test bench results (Engine Speed $1500 \mathrm{rpm}$, IMEP 9 bar). We turn off the control at $7.5 s$, we introduce an injection offset on cylinder 2 at $19 s$ and finally turn the controller back on at $36 s$. Top: IMEP from cylinder pressure sensors. Bottom: Individual Estimated AFR with the nonlinear observer

Simple issues such as control of AFR imbalance between the cylinders can be addressed by controlling the individual injection quantities (which is the relevant control strategy for such unbalance) with a PI controller. Figure 16 presents the results of such a control strategy relying on the individual AFR estimation. On the testbench, we turn off the control at $7.5 s$ which leads to the natural imbalance of the engine. We introduce an injection offset on cylinder 2 at $19 s$ and finally turn the controller back on at $36 s$. We see that the control is efficient and that we are able to balance the torque produced by each cylinder.

More advanced topics such as combustion real-time individual injection (masses, timing) control represent the long term goal of our work. The work presented here is a first step towards this. In all these cases, observers at $6^{\circ}$ crankshaft represent an new technology. This cutting edge technology is a major trend among the control community. It is made possible thanks to a complete tool chain ranging from efficient hardware (sensors and acquisition devices), simulator for algorithm synthesis and embedded systems (ACEbox).

\section{ACKNOWLEDGEMENTS}

The authors would like to thank Jérôme Vauchel and Sébastien Potteau for their important contribution on the experimental part, Antoine Albrecht for his contribution in the simulation part and Yann Creff and Michel Castagné for their support.

\section{REFERENCES}

1 Kahrstedt, J., Behnk, K.,Sommer, A., and Wormbs, T. (2003) Combustion processes to meet future emission standards. In MTZ, pages 1417-1423. 
2 Hultqvist, A., Engdar, U., Johansson, B., and Klingmann, J. (2001) Reacting boundary layers in a homogeneous charge compression ignition (HCCI) engine. In Proc. of SAE Conference, number 2001-01-1032.

3 Walter, B. and Gatellier, B. (2002) Development of the high power NADI ${ }^{T M}$ concept using dual mode Diesel combustion to achieve zero NOx and particulate emissions. In Proc. of SAE Conference, number 2002-01-1744.

4 Walter, B. and Gatellier, B., Miche, M. and Monteiro, L. (2004) Improvement of exhaust and noise emissions of the $\mathrm{NADI}^{T M}$ concept using pre-mixed type combustion with multiple stages injection. In SIA International Congress "Les Diesel aujourd'hui et demain”, Lyon, France.

5 Mathworks XPC Target 2 Support. http://www.mathworks.com.

6 Ranini, A., Potteau, S. and Gatellier, B. (2004) New developments of the NADI ${ }^{T M}$ concept to improve operating range, exhaust emissions and noise. In THIESEL Conference on Thermo- and Fluid Dynamic Processes in Diesel Engines, Valencia, Spain.

7 Gatellier, B., Ranini, A. and Castagné, M. (2004) New developments of the $\mathrm{NADI}^{T M}$ concept to improve operating range, exhaust emissions and noise. In Aachener Kolloquium Fahrzeug- und Motorentechnik, Aachen, Germany.

8 Albrecht, A., Corde, G., Knop, V., Boie, H. and Castagné, M. (2005) 1d simulation of turbocharged gasoline direct injection engine for transient strategy optimization. In Proc. of SAE Conference, number 2005-01-0693.

9 Lafossas, F., Colin, O., Le Berr, F. and Ménégazzi, P. (2005) Application of a new 1d combustion model to gasoline transient engine operation. In Proc. of SAE Conference, number 200501-2107.

10 Jaine, T., Benkenida, A., Ménégazzi, P. and Higelin, P. (2003) Zero dimensional computation of diesel spray - comparison with experiments and $3 \mathrm{~d}$ model. In $6^{\text {th }}$ International Conference on Engines for Automobile, Capri, Italy.

11 Chmela, F. and Orthaber, G. (1999) Rate of heat release prediction for direct injection Diesel engines based on purely mixing controlled combustion. In Proc. of SAE Conference, number 1999-01-0186.

12 Barba, C. and Burkhardt, C. (2000) A phenomenological combustion model for heat release rate prediction in high-speed DI Diesel engines with common rail injection. In Proc. of $S A E$ Conference, number 2000-01-2933.

13 Albrecht, A., Chauvin, J., Potteau, S. and Corde, G. (2005) Design of real-time torque balancing control for highly premixed combustion engine using a $1 \mathrm{~d}$ diesel engine model. In Proc. of the IAV Conference "Engine process simulation and supercharging".

14 L. Jianqiu, Y. Minggao, Z. Ming, and L. Xihao. Advanced torque estimation and control algorithm of diesel engines. In Proc. of SAE Conference, 2002.

15 Jianqiu, L., Minggao, Y., Ming, Z. and Xihao, L. (2002) Individual cylinder control of diesel engines. In Proc. of $S A E$ Conference, number 2002-01-0199.
16 Ginoux, S. and Champoussin, J.C. (1997) Engine torque determination by crankangle measurements: State of art, future prospects. In Proc. of SAE Conference, number 970532.

17 Gyan, P., Ginoux, S., Champoussin, J.C. and Guezennec, Y. (2000) Crankangle based torque estimation: Mechanistic/stochastic. In Proc. of SAE Conference.

18 Rizzoni, G. (1989) Estimate of indicated torque from crankshaft speed fluctuations: A model for the dynamics of the IC engine. Proc. in the IEEE Transactions on Vehicular Technology, 38,169-179.

19 Rizzoni, G. and Connolly, F. (1993) Estimate of IC engine torque from measurment of crankshaft angular position. In Proc. of SAE Conference.

20 Ball, J., Bowe, J., Stone, C. and McFadden, P. (2000) Torque estimation and misfire detection using block angular acceleration. In Proc. of SAE Conference.

21 Williams, J. (1996) An overview of misfiring cylinder engine diagnostic techniques based on crankshaft angular velocity measurements. In Proc. of SAE Conference.

22 Kiencke, U. and Nielsen, L. (2000) Automotive Control Systems For Engine, Driveline, and Vehicle. SAE Internationnal.

23 Fehrenbach, H. (1990) Model-based combustion pressure computation through crankshaft angular acceleration analysis. Proceedings of $22^{\text {nd }}$ International Symposium on Automotive Technology.

24 Chauvin, J., Corde, G., Moulin, P., Castagné, M., Petit, N. and Rouchon, P. (2004) Real-time combustion torque estimation on a Diesel engine test bench using an adaptive Fourier basis decomposition. In Proc. of the the 43rd IEEE Conf. Decision and Control.

25 Chauvin, J., Corde, G., Moulin, P., Castagné, M., Petit, N. and Rouchon, P. (2004) Observer design for torque balancing on a di engine. In Proc. of SAE Conference.

26 Grizzle, J., Dobbins, K. and Cook,J. (1991) Individual cylinder air-fuel ratio control with a single EGO sensor. Proc. in the IEEE Transactions on Vehicular Technology, 40,357-381.

27 Berggren, P. and Perkovic, A. (1996) Cylinder individual lambda feedback control in an SI engine. Master's thesis, Linköpings Universitet.

28 Fantini, J. and Burq, J.F. (2003) Exhaust-intake manifold model for estimation of individual cylinder air fuel ratio and diagnostic of sensor-injector. In Proc. of SAE Conference, number 200301-1059.

29 Carnevale, C. and Hadji, M. (1998) Cylinder to cylinder AFR control with an asymmetrical exhaust manifold in a GDI system. In Proc. of SAE Conference, number 981064.

30 Heywood, J. (1988) Internal Combustion Engine Fundamentals. McGraw-Hill, Inc.

31 Jensen, J., Kristensen, A., Sorensen, S., Houbak, N. and Hendricks, E. (1991) Mean value modeling of a small turbocharged diesel engine. In Proc. of SAE Conference, number 910070. 
32 Moraal, P. and Kolmanovsky, I. (1999) Turbocharger modeling for automotive control applications. In Proc. of SAE Conference, number 1999-01-0908.

33 Chauvin, J., Moulin, P., Corde, G., Petit, N. and Rouchon, P. (2005) Real-time nonlinear individual cylinder Air-Fuel Ratio observer on a Diesel engine testbench. In Proc. of the IFAC World Congress.
34 Chauvin, J., Moulin, P., Corde, G., Petit, N. and Rouchon, P. (2005) High frequency real-time individual cylinder Air Fuel Ratio observer on a Diesel engine. Control Engineering Practice (submitted).

35 Chauvin, J. (2005) Sensor dynamics inversion: Fourier based observers. Technical report, École des Mines de Paris.

Final manuscript received in June 2005 